University of South Florida

DIGITAL COMMONS

Digital Commons @ University of

@ UNIVERSITY OF SOUTH FLORIDA

South Florida

$1-30-2009$

\title{
2,4,6-Trinitrotoluene (TNT) Air Concentrations, Hemoglobin Changes, and Anemia Cases in Respirator Protected TNT Munitions Demilitarization Workers
}

Melville D. Bradley M.D.

University of South Florida

Follow this and additional works at: https://digitalcommons.usf.edu/etd

Part of the American Studies Commons

\section{Scholar Commons Citation}

Bradley, Melville D. M.D., "2,4,6-Trinitrotoluene (TNT) Air Concentrations, Hemoglobin Changes, and Anemia Cases in Respirator Protected TNT Munitions Demilitarization Workers" (2009). USF Tampa Graduate Theses and Dissertations.

https://digitalcommons.usf.edu/etd/1871

This Thesis is brought to you for free and open access by the USF Graduate Theses and Dissertations at Digital Commons @ University of South Florida. It has been accepted for inclusion in USF Tampa Graduate Theses and Dissertations by an authorized administrator of Digital Commons @ University of South Florida. For more information, please contact digitalcommons@usf.edu. 
2,4,6-Trinitrotoluene (TNT) Air Concentrations, Hemoglobin Changes, and Anemia Cases in Respirator Protected TNT Munitions Demilitarization Workers

by

Melville D. Bradley, M.D.

A thesis submitted in partial fulfillment

of the requirements for the degree of

Master of Science in Public Health

Department of Environmental and Occupational Health

College of Public Health

University of South Florida

Major Professor: Stuart Brooks, M.D.

Thomas Truncale, D.O.

Daisy Chang, Ph.D.

Date of Approval:

January 30, 2009

Keywords: Reticulocytosis, 4-Aminodinitrotoluene, Aplastic Anemia, Breathing Zone, Methemoglobin, Extravascular Hemolysis, Time Weighted Average.

(C) Copyright 2009, Melville Bradley 
The stated views are those of the author and do not represent the views or the policy of the Department of the Army or the Department of Defense. 


\section{Dedication}

To my loving wife, if not for her support this project would not have come to fruition. 


\section{Table of Contents}

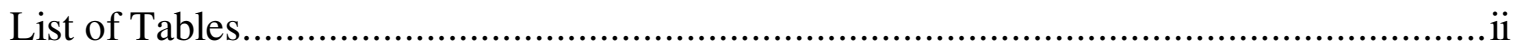

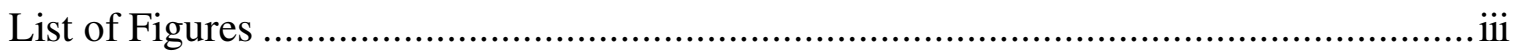

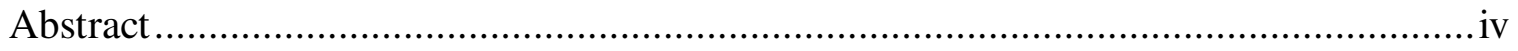

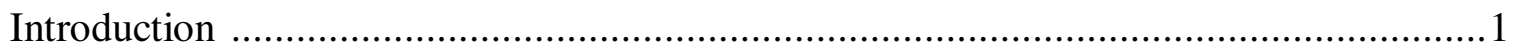

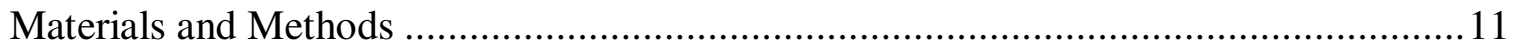

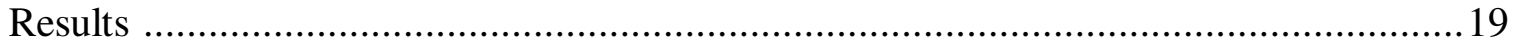

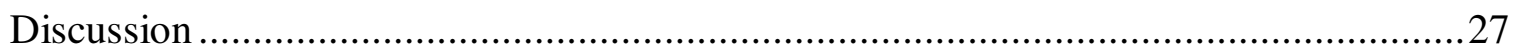

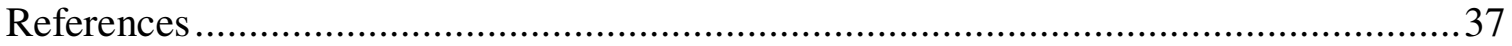




\section{List of Tables}

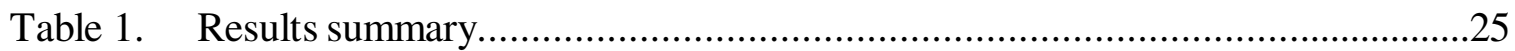

Table 2. Regression model summary and parameter estimates...............................25 


\section{List of Figures}

Figure 1. Mean hemoglobin changes regressed on mean TNT air concentrations for TNT concentration values $0.12 \mathrm{mg} / \mathrm{m}^{\wedge} 3$ to $0.31 \mathrm{mg} / \mathrm{m}^{\wedge} 3$. .....................26 
2,4,6-Trinitrotoluene (TNT) Air Concentrations, Hemoglobin Changes, and Anemia Cases in Respirator Protected TNT Munitions Demiltarization Workers.

\author{
Melville Bradley
}

\begin{abstract}
2,4,6-Trinitrotoluene (TNT) is an explosive used in munitions production that is known to cause both aplastic and hemolytic anemia in exposed workers. Deaths have been reported secondary to both varieties of anemia. Studies have shown that TNT systemic absorption is significant by both the respiratory and dermal routes. A literature review revealed that the most recent review article on TNT exposure arguing for a TWA drop from the PEL to the TLV was in 1977 - this article cited anemia issues in addition to other untoward effects of TNT. No studies encountered looked at hemoglobin change or anemia cases in respiratory protected workers - this present effort may be the first. TNT PEL $\left(1.5 \mathrm{mg} / \mathrm{m}^{\wedge} 3\right)$, REL $\left(0.5 \mathrm{mg} / \mathrm{m}^{\wedge} 3\right)$, and TLV $\left(0.1 \mathrm{mg} / \mathrm{m}^{\wedge} 3\right) 8 \mathrm{hr}$ TWAs all with skin notations (based on animal models and TNT urine metabolite extrapolation in TNT workers suggesting important role of skin absorption). The earliest effects of systemic TNT poisoning involve hgb and hematocrit drop.

The investigator hypothesized that respiratory protection alone is insufficient to protect TNT workers from the risk of anemia development and hemoglobin concentration drop. A retrospective observational study design was incorporated utilizing a records review of TNT vapor air concentration values and worker $\mathrm{Hgb}$ values for 8 sets of workers in respiratory protection at a demilitarization operation from October 2006 to April 2007 in order to observe whether or not respiratory protection provided adequate
\end{abstract}


protection against anemia development and hemoglobin change, and to help characterize the probable role of TNT skin absorption on hemoglobin change and anemia risk. Worker baseline hgbs were compared with their exposure hgbs for statistically significant hgb concentration changes (two-tailed paired t-tests), and anemia cases were recorded. Mean Hgb changes within each of the 8 groups of workers were then regressed on mean TNT air concentrations (10 hr TWAs) using air sampling that was performed closest in time to exposure hgbs.

Statistically significant hgb concentration drops and anemia cases were apparent at values about the REL and PEL in respiratory protected workers. There were no anemia cases or statistically significant hgb drops at values about the TLV, however. For TNT air concentarions from $0.12 \mathrm{mg} / \mathrm{m}^{\wedge} 3$ to $0.31 \mathrm{mg} / \mathrm{m}^{\wedge} 3$ there was strong positive linear association with regard to magnitude of hgb change ( $\mathrm{r}=0.996)$.

The results appear to confirm the necessity of the skin notation for TNT. However, the TLV seems to be protective against the possibility of anemia risk principally by the dermal route in workers who are respiratory protected. A question does still remain, however, as to anemia risk in workers who are below the TLV who may not be using respiratory protection. The absence of a continued linear association between mean TNT air concentrations and mean hgb change above the $0.31 \mathrm{mg} / \mathrm{m}^{\wedge} 3$ TNT level most likely reflects a marrow response, as the TNT levels evident in the study are reported to be mainly associated with extravascular hemolysis with a minimal, or non-existent, aplastic component assumed. This study adds evidence to the argument that the TLV should be adopted as the new PEL. 


\section{Introduction}

2,4,6-Trinitrotoluene (TNT) is a nitro-aromatic explosive compound used in the manufacture of munitions. Originally developed as a yellow dye in Germany by Joseph Wilbrand in 1863, it's use as an explosive in munitions production was only appreciated in 1902 when Germany began loading artillery shells with it. Since this time TNT has become the most widely used military explosive, and is the 'standard' high explosive (HE) against which all other high explosives have been, and continue to be, measured (DA Technical Manual (DA TM) 9-1300-214, 1984; Wikipedia, 2008). TNT (chemical formula $\mathrm{C} 6 \mathrm{H} 2(\mathrm{CH} 3)(\mathrm{NO} 2) 3)$, the first high explosive, has a detonation velocity greater than $22,000 \mathrm{ft} / \mathrm{sec}$. It is considered an insensitive explosive; insensitive explosives are characterized by their resistance to detonation by impact or friction. These properties, unlike nitroglycerin for example, allow TNT to be handled by workers in a relatively safe manner. TNT will burn in the presence of oxygen, but will explode in an oxygen deficient environment (such as a bomb body casing). Intrinsically safe capital goods are needed in plants that handle TNT to prevent fugitive electricity, static electricity, or certain radiofrequencies that could lead to detonation. Workers who work with open TNT must be conductive to dissipate any potential static electricity build up; this is best accomplished by the wear of conductive footwear, and cotton coveralls and caps (DA TM 0-1300-214; Bodeau, 1993). The following are some additional characteristics of TNT: Molecular weight 277.1 , boiling point $240 \mathrm{~F}$, detonation temperature $464 \mathrm{~F}$, melting point $176 \mathrm{~F}$, vapor pressure $0.0002 \mathrm{mmhg} \mathrm{NTP}$, solid yellow flake or crystals at NTP, 
Immediate danger to life and health (IDLH) $500 \mathrm{mg} / \mathrm{m}^{\wedge} 3, \mathrm{H} 20$ solubility at $77 \mathrm{~F} 0.01 \%$ (2,4,6-TNT MSDS, Zaklady Chemiczne, Wojska, Polskiego, 21Aug2003; 2,4,6-TNT, NIOSH Pocket Guide to Chemical Hazards, Sep2005).

TNT is not only a munitions worker safety hazard due to detonation and flammability potential, but is also a health hazard with a deadly track record of deaths secondary to aplastic anemia (as well as hepatic necrosis. TNT induced hepatic necrosis is beyond the scope of the present study and will not be addressed here. Other TNT related health problems outside of anemia also will not be elaborated on). Some historical numbers are sobering: In the US from 1914 to 1918 there were 24,000 recorded cases of TNT poisoning, of which 580 ended fatally, and in the UK from 1916 to 1941 there were 465 cases of poisonings, of which 125 were fatal (Bodeau, 1993). Individual susceptibilities certainly play a part, for example, with more deaths from hepatic necrosis seen in younger workers, and more deaths from aplastic anemia seen in older workers. There have also been deaths reported from massive hemolysis in those with glucose-6-phosphate deficiency. Indeed, anemia has been a traditional problem in the TNT explosive worker population, and has been supported by epidemiological studies as well as animal modeling (ACGIH, 2001; Army, 1976; Bodeau, 1993; Crawford, 1954; Djerassi \& Vitany, 1975; Hathaway, 1977; Hunter, 1978; LaDou, 2007; Opresko, 2004; Richter-Torres, Dorsey, \& Hodes, 1995; Sabbioni, Liu, Yan, \& Sepai, 2005). Although much is still unknown as to the mechanisms causing aplastic anemia, there is evidence, at least as far as the erythropoetic line is concerned, that TNT and/or a toxic metabolite suppresses delta-aminolevulinic acid synthase and heme synthase leading to early marrow hyperplasia followed by hypoplasia (Bodeau, 1993; Richter-Torres 1995). 
TNT's mechanism for causing hemolytic anemia is a bit better understood and is known to involve oxidative damage to red blood cells $(\mathrm{RBC})$ via the production of methemoglobin. The hemolysis is predominantly extravascular and involves splenic sequestration of damaged RBCs (Bodeau, 1993; Hunter, 1978; LaDou, 2007). It has been postulated that TNT hydroxyarylamine metabolites are responsible for hemoglobin oxidation (Liu, Lu, \& Steams, 1992), as well as for sulfinamide adducts with hemoglobin cysteine residues (Sabbioni, 2005).

Some specific examples from the literature concerning TNT induced anemia, hemoglobin drop, and anemia related deaths are as follows: Case series reports of TNT induced aplastic anemia deaths (Cone, 1944; Crawford, 1954; Eddy, 1944; Hart \& Ley, 1944; Hathaway, 1977; Hunter, 1978; McConnell \& Flinn, 1946; Voegtlin, Hooper, \& Johnson, 1921). Dacre and Rosenblatt (1974), showed no species difference with regard to anemia and hemolysis after oral feedings of TNT to cats, dogs, rabbits, and rats. Cone (1944) described the effects of TNT on formed elements of the blood, in particular RBC destruction. Hathaway (1977) suggests difficulty in formulating dose response relationships for airborne levels of TNT and observed toxic effects in man due to skin absorption problems and accidental ingestions. Animal anemia dose response to oral TNT dosing in rats and dogs was shown by Dilley and Tyson (1982), Levine, Furedi, \& Gordon (1984), and Levine, Rust, \& Barkley (1990). TNT induced hemolytic anemia deaths in 3 TNT workers with Glucose-6-phosphate dehydrogenase (G6PD) (Djerassi, 1975). Gribova, Gabulgalimova, \& Dymova (1983) in the USSR showed erythrocyte numbers and hemoglobin concentration reductions as a function of TNT air concentrations; the higher the TNT air concentrations, the lower the RBC count and 
hemoglobin concentration. The US Army (1976) did a cross sectional study of TNT workers versus non-TNT workers at 5 ammunition plants which revealed a low grade hemolysis with early compensatory reticulocytosis as a function of lower TNT air concentrations $\left(<0.5 \mathrm{mg} / \mathrm{m}^{\wedge} 3\right)$, but progressing to anemia and reduced reticulocytosis at levels above $0.5 \mathrm{mg} / \mathrm{m}^{\wedge} 3$. Non-exposed controls did not have these findings. Stewart, Witts, Higgins, \& O’Briens' (1945) study with pre-, during-, and post-TNT exposures in munitions workers showed a $9.6 \%$ to $14.2 \%$ hemoglobin drop with minimal reticulocytosis during exposure, but followed by an increasing reticulocytosis $48 \mathrm{hrs}$ post exposure; the air concentrations ranged between 0.3 and $1.3 \mathrm{mg} / \mathrm{m}^{\wedge} 3$. El Ghawabi \& Ibrahim (1974) showed a 15\% hemoglobin concentration drop in TNT exposed munitions workers versus no change in a non-exposed control group; exposure levels of TNT for exposed group ranged from 0.2 to $1.0 \mathrm{mg} / \mathrm{m}^{\wedge} 3$.

Systemic absorption of TNT in explosive workers is considered to be principally via the respiratory route necessitating respiratory protection once a time weighted average (TWA) standard is met (ie, OSHA $8 \mathrm{hr}$ permissible exposure limit (PEL) -TWA of $1.5 \mathrm{mg} / \mathrm{m}^{\wedge} 3$ for private industry, ACGIH $8 \mathrm{hr}$ Threshold limit value (TLV) -TWA of $0.1 \mathrm{mg} / \mathrm{m}^{\wedge} 3$ for government industry, and the NIOSH $8 \mathrm{hr}$ Recommended exposure limit (REL) - TWA of $0.5 \mathrm{mg} / \mathrm{m}^{\wedge} 3$ ). NIOSH minimal respiratory protection guidelines for TNT, per the NIOSH Pocket Guide to Chemical Hazards (2005), recommend any supplied-air respirator with an Assigned Protection Factor (APF) equal to 10 for TNT air concentrations up to $5 \mathrm{mg} / \mathrm{m}^{\wedge} 3$. A major concern addressed by numerous authors, however, is the importance of the skin absorption route, which some have suggested is the most important route of TNT absorption in exposed workers (Richter-Torres, 1995; 
Sabbioni, 2005; Hathaway, 1977; Hunter, 1978). These skin absorption observations are corroborated by dermal absorption studies in animal models using radiolabeled TNT (Richter-Torres 1995). Because of this skin absorption issue, NIOSH, OSHA, and the ACGIH all have a skin notation as part of their respective TWA standards. This suggests that (1) air monitoring alone may not be able to guarantee a healthful work environment, and that some sort of biological monitoring is required in addition; and (2) that respirator use alone may provide inadequate protection.

The following is a short overview on TNT metabolism and excretion. TNT can be absorbed via respiration, ingestion, and through intact skin. It is rapidly and completely metabolized as evidenced by lack of native substance (TNT) in the urine of humans and animals. Radiolabeled TNT in animal models has been shown to distribute to the blood, liver, kidney, spleen, lungs, brain, and skeletal muscle. One metabolic route is by the reduction of the TNT nitro groups to aminotoluenes followed by their oxidation to hydroxyarylamines via cytochrome $\mathrm{P} 450$. The other route is by the oxidation of the TNT methyl group to benzyl alcohol or benzoic acid. The last step involves benzyl alcohol and hydroxyarylamine conjugation with sulfuryl, glucuronide, and acetyl moieties. The major urine metabolites detected from this process are the aminotoluenes 4-aminodinitrotoluene (the major metabolite), 2-aminodinitrotoluene, 4-hydroxylamino2,6-dinitrotoluene, and amino-nitrocresol. The aminotoluene metabolites will clear within 48 hours of exposure cessation, and usually impart a dark red discoloration to the urine (which may be confused with hematuria / hemoglobinuria unless a UA rules this out) (Sabbioni, 2005; Richter-Torres, 1995; Channon \& Mills, 1944; Lemberg \& Callaghan, 1945; Bodeau 1993). 
There continues to be a search for a biological marker that will correlate with exposure and clinical effects, but this has not yet materialized; urinary metabolites clear quickly (within $48 \mathrm{hrs)}$ ) and do not correspond well to end organ damage (Sabbioni, 2005; author's experience). A promising venture by Sabbioni (2005) looked at the relationship between hemoglobin adducts of sulfinic acid amides (formed when TNT metabolite nitrosoarene reacts with cysteine residues) and toxic effects. Although somewhat promising for cataract, splenomegaly, and hepatomegaly when controlled for confounders, it is doubtful whether this test will come to fruition as a standardized test for TNT effects (Sabbioni, 2005). In the United States, TNT biological monitoring takes the form of medical monitoring (no BEI for TNT currently per the ACGIH) and is accomplished by routine labwork to look for organ damage before that damage manifests clinically. There is no OSHA standard for how medical surveillance and biological monitoring are to be accomplished for workers exposed to TNT, nor is there a known private industry consensus standard for health best practices. Large scale TNT use in the US is mainly evident at a big Department of the Army (DA) ammunition plant; there are other smaller TNT operations within the DA system, both government and contractor operated, but are usually of a smaller scale with adequate process isolation in place. Guidelines for medical monitoring within DA can be found in US Army Environmental Hygiene Agency study no. 32-049-75/76 (Army, 1976), and the Textbook of Military Medicine (Bodeau, 1993). TNT used to fill munitions at these facilities is usually imported, or obtained by TNT reclamation projects (TNT has not been manufactured extensively in the US for many years). The paucity of TNT manufacture, and its limited utilization may be the reasoning behind the lack of health regulation outside of the PEL 
here in the US. The routine labwork for medical monitoring that was performed at the author's plant consisted of a complete blood count for anemia surveillance (CBC), liver function tests for hepatitis surveillance, lactate dehydrogenase (LDH) and urinalysis (UA) to support abnormalities of the CBC or LFTs (Bradley, 2005). Also utilized was a hand held pulse oximeter (since replaced by a co-oximeter at this writing) to obtain an indirect measure of methemoglobinemia (for a brief review of pulse oximetry and cooximeter use in methemoglobinemia evaluation, I refer the reader to page 7 of the online emedicine article by Kumar, M from 1Aug2003 entitled Methemoglobinemia. TNT induced methemoglobinemia will not be addressed further in the present writing). Of the above medical monitoring, the earliest manifestation of TNT induced change involved pulse oximeter reading spO2 drops, and hemoglobin / hematocrit drop in the CBC (Richter-Torres, 1995; author's experience). The red blood cell (RBC) indices usually remain normal; even when hemoglobin drops to the point of anemia, the indices were still usually within normal limits (ie, normochromic, normocytic anemia) (Army, 1976; Crawford, 1954; Hathaway, 1977; author's experience). The hemoglobin and hematocrit drops, according to Bodeau (1993), appear to be concentration dependent at TNT TWAs between $0.2-0.5 \mathrm{mg} / \mathrm{m}^{\wedge} 3$; this is supported by Gribova (1983) who also demonstrated a concentration dependency, and by studies cited in the TNT ATSDR Profile (RichterTorres, 1995). Nothing was mentioned as to whether or not the workers in these studies were in respiratory protection; nor was there any mention of the hemoglobin drops being linear as a function of the TNT air concentrations.

The American College of Governmental Industrial Hygienists (ACGIH) adopted its current TNT TLV of $0.1 \mathrm{mg} / \mathrm{m}^{\wedge} 3$ in 1997 based principally on the German TNT 
Arbeitsplatzgrenzwerte of the same concentration (Deutsche Forschungsgemeinschaft (DFG), 1991). The ACGIH authors cite the DFG: Occupational Toxicants studies on TNT (pp359-387), Gribova (1983), and Hathaway (1977) stating that "altered liver parameters were seen in workers exposed to 0.3 to $0.8 \mathrm{mg} / \mathrm{m}^{\wedge} 3$, and changes in hematologic parameters were seen in workers exposed to 0.05 to $7.5 \mathrm{mg} / \mathrm{m}^{\wedge} 3$ ” (ACGIH, 2001). Despite evidence going back years, OSHA continues to maintain a PEL of $1.5 \mathrm{mg} / \mathrm{m}^{\wedge} 3$. There is certainly substantial evidence for a lowering of the PEL to the present TLV level; this was in fact argued by Hathaway (1977) when he authored a review article (which is used as a reference in this paper) arguing for a drop to the then TLV of $0.5 \mathrm{mg} / \mathrm{m}^{\wedge} 3$. Furthermore, according to Bodeau’s (1993) review, he discovered that of 21 recorded TNT fatalities from aplastic anemia and toxic hepatitis during World War II that had air sampling data, only $1 / 3$ of these were over $1.5 \mathrm{mg} / \mathrm{m}^{\wedge} 3$ (which in the 1940s was the TLV (MAC-TWA), and is still today the PEL). Usual industrial hygiene controls for TNT exposure may include process isolation, substitution (ie, changing from TNT to another HE like PBX), education and training, local exhaust ventilation, administrative controls (such as job rotation, showering, plant provided garments, clean side/dirty side changing areas, etc.), and personal protective equipment (air line respirator, or air purifying negative pressure with combination HEPA and organic vapor cartridges; also cotton coveralls, cotton caps, gloves, and conductive steel toe boots for static dissipation).

The literature review for this paper was somewhat difficult as there was an inability to procure various primary sources, and therefore reliance on some review articles became necessary. The review articles utilized were all very good and quite 
comprehensive. There is not a great deal of contemporary research being done on TNT presently outside of Sabbioni's group out of Switzerland (of which 2 articles are used here), and most of the primary literature goes back to the 40's through 70's timeframe, as well as articles from the old eastern block and Soviet Union. Of note, is that none of the studies involving TNT induced anemia in workers involved workers using respiratory protection; and neither does the ACGIH reference respirator use in any of the studies it utilized to justify their latest TLV. The skin notation evident for the TLV appears to be justified principally by (1) animal studies confirming a dermal absorption (see above), and (2) by disproportionate quantities of urine metabolites at certain air concentrations that could not be explained by the respiratory route alone (ACGIH, 2001; Woolen, Hall, \& Craig, 1986). Historically, the ACGIH adopted the skin notation for TNT back in 1961 based on animal models and worker observations, leading to the adoption of the notation by NIOSH and OSHA when these entities came into existence in the 1970s (OSHA adopted all of the 1969 TLVs as their PELs).

The objective of this present study is to corroborate the need for the skin notation by investigating if respiratory protected TNT workers are at risk for hemoglobin concentration drop and /or anemia development (the earliest systemic change secondary to TNT toxicity); no study thus encountered has looked at the skin absorption issue from the point of view of respiratory protected workers. The hypothesis propagated is that, based on the importance of the skin absorption route, respirator use alone is insufficient to provide protection against hemoglobin concentration drop and/or anemia cases in workers working around open molten TNT. 
The target population is respirator protected TNT munitions workers who work with open molten TNT who may be at risk for hemoglobin drop and/or anemia development via the TNT skin absorption route. 


\section{Materials and Methods}

A retrospective observational study was chosen where TNT exposed workers served as their own controls; no independent control group was used. The data had been procured prospectively by repeated surveys when the investigator ran the TNT medical monitoring program at the Ammunition Plant; the specific timeframe retrospectively reviewed was between October 2006 and April 2007. The data includes worker baseline hemoglobin concentrations, follow-up hemoglobin concentrations during TNT exposure, and breathing zone and/or general area air sampling for TNT vapor done as close in time as possible to the follow-up hemoglobin lab work.

The convenience samples consisted of 6 groups of respiratory protected (North or $3 \mathrm{M}$ full face negative pressure air purifying respirators supplied with combination organic vapor and HEPA filter cartridges) muntions demilitarization workers who worked in a TNT melt-out facility, who were exposed to TNT vapor, and were at risk for TNT skin absorption between October 2006 and April 2007 (2 of these 6 groups were night shift); and an additional 2 groups from another facility involved in a bomb loading operation that were respiratory protected (positive pressure air-line), but at risk for TNT skin absorption in October 2006 and February 2007. These workers' additional PPE ensembles consisted of rubber gloves, conductive steel toe boots, flame retardant cotton coveralls and cotton caps. This PPE garb is intended to stave off any potential for detonation due to static build-up, but provides no protection from TNT vapor skin contact. The workers' caps, coveralls and work undergarments were provided and 
laundered by the plant. The respiratory protection program followed the tenets of 29CFR1910.134 and included medical clearances, annual quantitative fit testing, worker training, respirator storage / cleaning / maintenance, cartridge change-outs, etc.

Eight data sets were generated corresponding to the aforementioned 8 groups of workers where, for each group, mean hemoglobin level changes were calculated using the individual workers pre-exposure baselines and during-exposure follow-ups. A two-tailed paired t-test was used for each group of workers to see which group(s) had a statistically significant mean hemoglobin concentration change during TNT exposure; 95\% confidence intervals were also determined. Hemoglobin concentration is normally distributed in the population, and for purposes here the null hypothesis is no mean hemoglobin concentration change, with the alternative being during- exposure mean hemoglobin concentration change compared with pre-exposure baseline. These t-tests were conducted at an alpha level of 0.05 . Since group hemoglobin change observations over time was not a goal in this study, a repeated measures ANOVA was not incorporated (goal was to take cross-sections and look for group hemoglobin changes as a function of the mean/median TNT air concentrations at discrete points in time; and to identify anemia cases that needed to be pulled from the TNT operations, per plant SOP). The 8 groups varied in size between 12 and 19 workers. Baseline pre-exposure labwork, by SOP (Bradley, 2004), were all less than 1 year old. Follow-up during exposure labwork would ideally have been conducted post-shift, post-workweek; but due to administrative issues was usually done on Mondays post-shift. This is not as detrimental as it appears. Weekend recovery was considered to be minimal because in our experience of pulling anemics out of open TNT areas, the amount of recovery time needed away from TNT 
was usually between 30 and 60 days (occasionally we had recovery at 2 weeks). All complete blood counts (CBCs) were sent to the clinic's Joint Commission accredited contract laboratory in the town's regional medical center for processing.

Corresponding to the mean hemoglobin changes calculated above, all breathing zone (BZ) and general area (GA) TNT vapor concentration air sampling values were obtained closest in time to each groups' follow-up during-exposure labwork. Numbers of samplings varied between each group and ranged between 2 and 8 samples each. The industrial hygiene section utilized the OSHA TNT air sampling organic method \#44 (OSHA, 1983) and calculated out a $10 \mathrm{hr}$ TWA per sample (the workweek was 4 days, 10 $\mathrm{hr}$ shifts). The samples were taken over the full duration of the shifts and were monitored by an on site industrial hygiene technician. Most of the BZs taken involved the pump being placed on more than one worker as the workers rotated through the facilities' work stations (job rotation was implemented as the main administrative control, but BZ workstation evaluations were ongoing not only as a means of monitoring worker exposure, but also to gage ongoing attempted engineering fixes to reduce the TNT vapor concentrations about the timeframe of this study. The plant, by federal regulation, fell under the TNT TLV-TWA of $0.1 \mathrm{mg} / \mathrm{m}^{\wedge} 3$, or $0.08 \mathrm{mg} / \mathrm{m}^{\wedge} 3$ for the $10 \mathrm{hr}$ plant shifts even though most of the time the air sampling was below the OSHA PEL-TWA of $1.5 \mathrm{mg} / \mathrm{m}^{\wedge} 3$, or $1.2 \mathrm{mg} / \mathrm{m}^{\wedge} 3$ for $\left.10 \mathrm{hrs}\right)$. The samples were analyzed at the plant's explosive laboratory using the OSHA method \#44 where samples were desorbed with acetone and analyzed by gas chromatography using a thermal energy analyzer (TEA) with an explosives analysis package (EAP). Assuming normal distribution of TNT vapor, means for each of the 8 groups were calculated mainly for regression modeling purposes. Medians were also 
calculated, as true distribution may be lognormal due to sampling selection methodology (Perkins, 1997). Small sample sizes for each of the 8 groups (between 2 and 8 each) is a limitation inherent in this study. Both means and medians, therefore, are recorded in the results section along with their corresponding mean hemoglobin concentration change analyses.

Simple linear regression modeling analysis at an alpha of 0.05 was performed with mean hemoglobin concentration changes regressed on corresponding mean TNT vapor concentrations.

Clinical significance in hemoglobin concentration reduction was defined as any drop in hemoglobin that fell below the lower laboratory limit of normal (anemia: $<12.2 \mathrm{~g} / \mathrm{dL}$ for females and $<14.1 \mathrm{~g} / \mathrm{dL}$ for males) and/or a hemoglobin drop of greater than $2 \mathrm{gm} / \mathrm{dL}$ within 1 month even if the drop was contained within the reference laboratory's normal reference range.

Since study design was observational, the following were the default selection inclusion criteria: Healthy workers not controlled for age (older employees given counseling on their increased risk of TNT induced anemia), sex, ethnicity, smoking status, alcohol use (employees who used alcohol cautioned about TNT's and alcohol's association with hepatitis), SES, BMI, duration of time in TNT facility (including carryover from one follow-up to another. Duration of time only controlled by clinic when worker(s) was pulled from open TNT work due to the above criteria of becoming anemic, or having a hemoglobin drop of greater than $2 \mathrm{gm} / \mathrm{dL}$ within the normal range), and duration of time at particular work station due to job rotation; but controlled for respiratory exposure to TNT vapor via respiratory protection. 
By plant's TNT biological monitoring SOP (Bradley, 2005) selection exclusion criteria included the following: Pre-existing anemia of any cause (if menses a cause, must have normal $\mathrm{H} / \mathrm{H}$ off cycle), pre-existing liver disease and/or elevated liver function tests (LFTs), G6PD deficiency, any medications such as isoniazid, phenylbutazone, phenytoin, methotrexate, and others that have the potential to cause marrow suppression, cholestasis, or heptatocellular necrosis, etc. (permitted those with daily acetominophen use or HMG-CoA reductase inhibitor use if LFTs were within normal limits), any medical conditions that would predispose to anemia of chronic disease (ie, Hepatitis, poorly controlled diabetes mellitus, etc.), any conditions that may worsen with induced anemia (COPD, ASCAD, ASPVD, CHF, etc.), pregnancy (left choice to female, by SOP recommendation is to stay out; clinic educated female on dangers to fetus of TNT exposure), any TNT induced anemics who have not yet recovered after removal, and any condition that would be disqualifying for negative pressure air purifying respirator use.

The following is a step by step outline of the munition demilitarization / TNT reclamation process in the facility where the aforementioned 6 groups of workers were working: (1) Fork truck moves pallet of $750 \mathrm{lb}$ bombs from boxcar to holding area where de-palletization occurs. (2) Fork truck lifts $750 \mathrm{lb}$ bombs onto breakdown/roll table where base plate and cone tip are removed and bomb body is wiped down. (3) Temporary base plate is installed to accommodate scissor hoist. (4) Bomb rolled on table to steam out operation of fuse well (hot steam emitted via a cone which fits over fuse well area in order to loosen the tar binding, well is then removed via specialized tool and placed into grade 1 scrap bin). (5) Bomb is then rolled to tilt table. (6) Tilt table takes bomb from horizontal position to vertical position nose down. (7) Scissor hoist is then 
placed around temporary baseplate. (8) Bomb is then hoisted 3 levels up to copula area where the autoclaving operation takes place. (9) Bomb is placed into autoclave and sealed; it will cook for around 4 hours at a temperature range of 180 to 200 degrees Farenheit (melting temperature of TNT). (10) Melted out TNT exits the nose cone area through the fuse well opening and is conduited via gravity through an insulated enclosed trough system to a kettle with hot holding temperature of 180F. (11) Molten TNT then exits kettle through an enclosed trough in a controlled fashion onto an enclosed extruder belt which is water cooled from below. (12) Along the extruder belt length the molten TNT is cooled until it is re-solidified as flake by the belt's end. (13) TNT flake is then collected in plastic bags within cardboard boxes in an enclosed flake room at the extruder belt's end; when a box is full it is conveyed out of the flake room via a belt system to the weighing and QA stations. (14) Box is then sealed, labeled, and palletized. (15) Meanwhile, back up in the autoclave area above: Empty bomb body is hoisted out of the autoclave and lowered back down to tilt table where scissor hoist and temporary base plate is removed (temporary base plate is recycled back to the breakdown table). (16) Bomb is then re-oriented from the vertical to the horizontal in the tilt table. (17) Bomb body is then rolled out of tilt table onto roll table where the explosive well of the bomb body is scraped out to remove remnants of the tar lining (tar lining provides insulation between the metal portion of the bomb body and the explosive charge). (18) When bomb body is certified TNT and tar free it is moved by fork truck to grade 1 scrap holding area outside the building. (19) Reclaimed palletized TNT is trucked out of facility to an indoor storage area; and fuse wells and bomb bodies are trucked to an outside grade 1 scrap storage area. 
The major source of TNT vapor exposure within the demil facility were two open areas of the trough gallery on the mezzanine level between the ground level and the copula where the autoclaves were; right about in the center of the building. The aforementioned step-by-step process was designed to be a closed process with an apparently robust exhaust ventilation system, but one problem evidently had not been foreseen. The problem involved the unanticipated melting out of some of the bomb bodies' tar lining along with the TNT. The molten tar lining contaminates the reclaimed TNT and hence is a QA issue, and it also tends to clog up the trough and kettle systems. Another less important source of TNT vapor was a removed panel from the side of the enclosed extruder belt housing which allowed for the escape of water vapor (as well as TNT vapor); the water vapor from the belt cooling system would contaminate the TNT (there is a QA standard for what an acceptable amount of water content is permitted in the product - ie, TNT purity). Some grab samples in the building revealed a TNT vapor concentration gradient from these 2 sources outward (these two sources were very close to one another, one being on the mezzanine, and the other almost directly below on the ground level). Also, there were some fugitive emissions from the opening of the autoclaves when spent bomb bodies were removed (2-3 times per day for about half an hour). As of yet the engineering solutions for these problems have not materialized. There is now a necessity for a mezzanine work station where workers called tar dippers ladle out clumps of tar from the trough system at a point just under the autoclaves but before the kettle; this is the reason for the breach in the enclosed trough gallery system mentioned above. Part of the job rotation objectives alluded to earlier is to relieve the tar 
dippers (ie, everyone gets a turn now) as the mezzanine level appears to be the point of maximum TNT exposure.

The operation's worker numbers and work stations are as follows: 1 supervisor, 1 fork lift operator, 2-3 breakdown table, 2-3 fuse well steam out, 2-3 bomb scraping, 1 extruder belt / kettle operator, 1-2 autoclave operators, 2-3 tar dippers, 1 flake room worker, 1 weigher / palletizer, 1 QA inspector. 


\section{Results}

The results of the statistical analyses performed using SPSS 16.0 statistical software showed no statistically significant mean hemoglobin changes and no anemia cases at the following mean TNT air concentration values: $0.12 \mathrm{mg} / \mathrm{m}^{\wedge} 3,0.23 \mathrm{mg} / \mathrm{m}^{\wedge} 3$, and $0.27 \mathrm{mg} / \mathrm{m}^{\wedge} 3$ (median values respectively, $0.07 \mathrm{mg} / \mathrm{m}^{\wedge} 3,0.16 \mathrm{mg} / \mathrm{m}^{\wedge} 3$, and $\left.0.10 \mathrm{mg} / \mathrm{m}^{\wedge} 3\right)$. There were, however, statistically significant mean hemoglobin changes and anemia cases at the following mean TNT air concentration values: $0.31 \mathrm{mg} / \mathrm{m}^{\wedge} 3$, $0.47 \mathrm{mg} / \mathrm{m}^{\wedge} 3(\mathrm{x} 2), 0.7 \mathrm{mg} / \mathrm{m}^{\wedge} 3$, and $1.31 \mathrm{mg} / \mathrm{m}^{\wedge} 3$ (median values respectively, $0.27 \mathrm{mg} / \mathrm{m}^{\wedge} 3,0.47 \mathrm{mg} / \mathrm{m}^{\wedge} 3(\mathrm{x} 2), 0.40 \mathrm{mg} / \mathrm{m}^{\wedge} 3$, and $\left.1.24 \mathrm{mg} / \mathrm{m}^{\wedge} 3\right)$; the mean hemoglobin changes here were reductions in hemoglobin concentrations during TNT exposure compared to concentrations pre-exposure.

When mean hemoglobin changes were regressed on mean TNT air concentrations utilizing a simple linear regression model, a statistically significant linear association was revealed for mean TNT air concentrations from $0.12 \mathrm{mg} / \mathrm{m}^{\wedge} 3$ to $0.31 \mathrm{mg} / \mathrm{m}^{\wedge} 3$. Mean TNT air concentrations between $0.31 \mathrm{mg} / \mathrm{m}^{\wedge} 3$ and $1.31 \mathrm{mg} / \mathrm{m}^{\wedge} 3$, however, showed no such statistically significant association with mean hemoglobin changes; this finding most likely may be explained by bone marrow compensation at these higher TNT concentrations.

The following are the results and analyses for each of the 8 groups of workers. This is then followed by the regression modeling for the 4 lowest mean TNT concentration values. 
Group 1 dayshift demil operation with air sampling date $310 c t 06$ and hgb followup date of 13 Nov06. Mean air sampling $0.12 \mathrm{mg} / \mathrm{m}^{\wedge} 3$; median air sampling $0.07 \mathrm{mg} / \mathrm{m}^{\wedge} 3$. Mean hgb change (baselines minus follow-ups) $-0.28 \mathrm{~g} / \mathrm{dL}$ (ie, improvement with exposure at these TNT air concentrations). $95 \%$ CI $(-0.714,0.154)$, and a $\mathrm{p}=0.189$ on 2 tailed paired t-test. No anemia cases.

$\mathrm{Hgb}$ concentration $(\mathrm{g} / \mathrm{dL})$ pairings for each worker pre-exp minus during-exp: 16.1-15.9; 14.2-16.2; 14.8-14.3; 13.4-13.7; 16.8-17.1; 13.8-13.1; 14.8-15.0; 15.8-16.4; $12.9-13.5 ; 15.7-15.0 ; 14.1-14.5 ; 16.5-15.8 ; 15.7-15.9 ; 13.6-14.9 ; 14.8-15.9$.

TNT air sampling (in $\mathrm{mg} / \mathrm{m}^{\wedge} 3 ; 10 \mathrm{hr}$ TWAs): Desk (GA) 0.05 , fork truck (BZ) 0.05, autoclaves (BZ) 0.07, scraping (BZ) 0.03, mezzanine (BZ) 0.40, extruder (BZ) 0.07, flake room (BZ) 0.20, box weigh (BZ) 0.08 .

Notes: Natural dilution ventilation for around 2-3 weeks secondary to warmer weather. All bay and personnel doors left open. Workers in 3M or North full face negative pressure air purifying respirators supplied with combination organic vapor and HEPA filter cartridges.

Group 2 nightshift demil operation with air sampling date 15Mar07 and hgb follow-up date of 19Mar07. Mean air sampling $0.23 \mathrm{mg} / \mathrm{m}^{\wedge} 3$; median air sampling $0.16 \mathrm{mg} / \mathrm{m}^{\wedge} 3$. Mean hgb change (baselines minus follow-ups) $0.125 \mathrm{~g} / \mathrm{dL}$ (ie, follow-up conc less than baseline conc). $95 \% \mathrm{CI}(-0.258,0.510)$, and $\mathrm{p}=0.489$ on 2 tailed paired $\mathrm{t}-$ test. No anemia cases.

$\mathrm{Hgb}$ concentration $(\mathrm{g} / \mathrm{dL})$ pairings for each worker pre-exp minus during-exp: 13.0-13.3, 13.6-14.3, 15.2-16.0, 16.2-15.7, 13.8-14.1, 14.2-14.8, 14.6-14.6, 13.8-14.2, 15.1-14.3, 15.9-16.7, 14.7-14.3, 15.7-14.8, 16.2-15.0, 16.2-16.0, 14.6-14.1, 15.2-13.8. 
TNT air sampling $\left(\mathrm{mg} / \mathrm{m}^{\wedge} 3 ; 10 \mathrm{hr}\right.$ TWAs): Mezzanine (GA) 0.44, extruder (GA) 0.29, breakdown (GA) 0.16, desk (GA) 0.16, autoclaves (GA) 0.12.

Notes: Tar screen attempted as engineering fix so mezzanine trough sections that remained open for tar dipping procedure could be closed. Screen was installed further downstream just before kettle (turned out to be impractical as screens would clog quickly with tar and back up the trough system - no way to know visually when back up occurred as trough system closed). Screen process in place for about 1-2 weeks. Workers in 3M or North full face negative pressure air purifying respirators supplied with combination organic vapor and HEPA filter cartridges.

Group 3 dayshift straight pour loading operation with air sampling date 28Feb07 and hgb follow-up date of 12 Mar07. Mean air sampling $0.27 \mathrm{mg} / \mathrm{m}^{\wedge} 3$; median air sampling $0.10 \mathrm{mg} / \mathrm{m}^{\wedge} 3$. Mean hgb change (baselines minus follow-ups) $0.358 \mathrm{~g} / \mathrm{dL}$ (ie, hgb concentration drop during TNT exposure compared to baseline). 95\% CI (-0.065, 0.782), and $\mathrm{p}=0.09$ on 2 tailed paired $\mathrm{t}$-test. No anemia cases.

$\mathrm{Hgb}$ concentration $(\mathrm{g} / \mathrm{dL})$ pairings for each worker pre-exp minus during-exp: 15.3-14.9, 15.9-14.6, 15.5-15.4, 15.5-14.4, 15.7-14.8, 16.1-16.1, 15.6-14.9, 14.5-14.9, 14.4-13.3, 14.8-15.2, 14.8-14.6, 15.6-16.3.

TNT air sampling $\left(\mathrm{mg} / \mathrm{m}^{\wedge} 3 ; 10 \mathrm{hr}\right.$ TWAs): TNT tinhorns (GA) 0.01, desk (GA) 0.1, mixing (BZ) 1.1, pellet breaking (BZ) 0.06, bomb filling (BZ) 0.1 .

Notes: New exhaust ventilation system installed; new modifications made since Sep2006. All workers in air-line positive pressure respirators. No breakthrough on under hood sampling. 
Group 4 dayshift demil operation with air sampling date $12 \mathrm{Oct} 2006$ and hgb follow-up date of the same 12Oct2006. Mean air sampling $0.31 \mathrm{mg} / \mathrm{m}^{\wedge} 3$; median air sampling $0.27 \mathrm{mg} / \mathrm{m}^{\wedge} 3$. Mean hgb change (baselines minus follow-ups) $0.594 \mathrm{~g} / \mathrm{dL}$ (ie, hgb concentration drop during TNT exposure compared to baseline). 95\% CI ( 0.277 , 0.910 ), and $\mathrm{p}=0.001$ on 2 tailed paired t-test. 4 anemia cases.

$\mathrm{Hgb}$ concentrations ( $\mathrm{g} / \mathrm{dL}$ ) pairings for each worker pre-exp minus during-exp: $16.8-16.8,14.8-13.8,13.6-14.3,13.8-12.2,15.8-15.2,16.3-16.1,17.0-15.8,13.2-12.3$, 14.1-13.0, 14.1-13.2, 13.4-13.4, 16.4-15.7, 16.5-15.2, 14.8-14.8, 14.5-14.0, 15.7-15.4. TNT air sampling $\left(\mathrm{mg} / \mathrm{m}^{\wedge} 3 ; 10 \mathrm{hr}\right.$ TWAs; all BZs): boxing tnt 0.16 , autoclaves 0.27 , mezzanine 0.50 , flake room 0.39 , extruder 0.23 .

Notes: Workers in 3M or North full face negative pressure air purifying respirators supplied with combination organic vapor and HEPA filter cartridges.

Group 5 dayshift demil operation with air sampling date 19Apr2007 and hgb follow-up date of 23Apr2007. Mean air sampling $0.47 \mathrm{mg} / \mathrm{m}^{\wedge} 3$; median air sampling $0.47 \mathrm{mg} / \mathrm{m}^{\wedge} 3$. Mean hgb change (baselines minus follow-ups) $0.478 \mathrm{~g} / \mathrm{dL}$ (ie, hgb concentration drop during TNT exposure compared to baseline). 95\% CI (0.081, 0.875), and $\mathrm{p}=0.021$ on 2 tailed paired $\mathrm{t}$-test. 3 anemia cases.

$\mathrm{Hgb}$ concentration $(\mathrm{g} / \mathrm{dL})$ pairings for each worker pre-exp minus during-exp: 14.8-14.0, 14.5-14.0, 14.8-14.5, 16.0-14.9, 14.1-14.3, 15.8-16.0, 14.3-14.9, 16.8-15.7, 15.7-14.3, 13.4-13.6, 15.7-15.3, 14.4-14.4, 14.3-14.7, 14.8-13.9, 14.8-14.8, 16.7-14.0, $15.9-15.1,15.7-15.5$.

TNT air sampling $\left(\mathrm{mg} / \mathrm{m}^{\wedge} 3 ; 10 \mathrm{hr}\right.$ TWAs; all GAs): North mezzanine 0.17 , Mid mezzanine 0.77 . 
Notes; Paucity of air sampling done on sampling date. 2 TWAs calculated for sampling that was focusing on the mezzanine area with open trough section and tar dipper(s) work station. These sections of open trough considered major source of entire building elevated TNT levels. Workers in 3M or North full face negative pressure air purifying respirators supplied with combination organic vapor and HEPA filter cartidges.

Group 6 nightshift demil operation with air sampling date 19Apr2007 and hgb follow-up date of 24Apr2007. Mean air sampling $0.47 \mathrm{mg} / \mathrm{m}^{\wedge} 3$; median air sampling $0.47 \mathrm{mg} / \mathrm{m}^{\wedge} 3$. Mean hgb change (baselines minus follow-ups) $0.493 \mathrm{~g} / \mathrm{dL}$ (ie, hemoglobin concentration drop during TNT exposure compared to baseline). 95\% CI $(0.215,0.771)$, and $\mathrm{p}=0.002$ on 2 tailed paired $\mathrm{t}$-test. 1 anemia case.

$\mathrm{Hgb}$ concentration $(\mathrm{g} / \mathrm{dL})$ pairings for each worker pre-exp minus during-exp: 15.4-15.5, 14.2-13.8, 16.1-15.4, 14.3-14.7, 14.8-14.7, 15.1-14.2, 15.5-15.0, 14.7-14.2, $15.7-14.6,15.8-15.7,16.2-15.8,15.0-14.4,16.2-14.8,16.2-15.4$.

TNT air sampling $\left(\mathrm{mg} / \mathrm{m}^{\wedge} 3 ; 10 \mathrm{hr}\right.$ TWAs; all GAs): North mezzanine 0.17 , midmezzanine 0.77 .

Notes: See group 5 notes above.

Group 7 dayshift demil operation with air sampling date 30Jan2007 and hgb follow-up date of $8 \mathrm{Feb} 2007$. Mean air sampling $0.70 \mathrm{mg} / \mathrm{m}^{\wedge} 3$; median air sampling $0.40 \mathrm{mg} / \mathrm{m}^{\wedge} 3$. Mean hgb change (baselines minus follow-ups) $0.577 \mathrm{~g} / \mathrm{dL}$ (ie, hgb concentration drop during TNT exposure compared to baseline). $95 \% \mathrm{CI}(0.20,0.95)$, and $\mathrm{p}=0.006 .4$ anemia cases. 
Hgb concentrations (g/dL) pairings for each worker pre-exp minus during exp: 16.8-16.2, 13.4-13.5, 14.5-13.2, 15.7-14.0, 14.3-13.6, 14.8-14.7, 14.8-14.9, 14.8-13.2, $15.7-14.9,14.7-14.4,16.3-16.0,15.4-15.0,14.4-14.5$.

TNT air sampling $\left(\mathrm{mg} / \mathrm{m}^{\wedge} 3 ; 10 \mathrm{hr}\right.$ TWAs): Mezzanine (BZ) 2.0, desk (GA) 0.3, autoclaves (BZ) 0.4, flake room (BZ) 0.5, tnt boxing (BZ) 0.4.

Notes: Cold weather, all bay and personnel doors closed. Workers in 3M or North full face negative pressure air purifying respirators supplied with combination organic vapor and HEPA filter cartridges.

Group 8 dayshift loading operation (straight pour with tamping/stemming) with air sampling date 28Sep2006 and hgb follow-up date of 10Oct2006. Mean air sampling $1.31 \mathrm{mg} / \mathrm{m}^{\wedge} 3$; median air sampling $1.24 \mathrm{mg} / \mathrm{m}^{\wedge} 3$. Mean hgb change (baselines minus follow-ups) $0.49 \mathrm{~g} / \mathrm{dL}$ (ie, hgb concentration drop during TNT exposure compared to baseline). $95 \% \mathrm{CI}(0.056,0.923)$, and $\mathrm{p}=0.029$ on 2 tailed paired $\mathrm{t}$-test. 3 anemia cases. $\mathrm{Hgb}$ concentration $(\mathrm{g} / \mathrm{dL})$ pairings for each worker pre-exp minus during-exp: 14.8-14.8, 16.7-14.4, 12.5-13.0, 14.8-14.7, 15.9-15.0, 15.5-16.1, 16.0-15.4, 14.0-13.7, 16.9-16.5, 16.1-16.5, 15.3-15.0, 15.6-16.2, 13.9-13.5, 14.5-15.0, 15.7-15.5, 13.5-11.6, $15.5-14.3,15.3-14.0,13.4-11.4$.

TNT air sampling $\left(\mathrm{mg} / \mathrm{m}^{\wedge} 3 ; 10 \mathrm{hr}\right.$ TWAs): pellet breaking (BZ) 2.68, pouring (BZ) 1.2, tamping/stemming (BZ) 1.28, desk (GA) 0.08 .

Notes: New exhaust ventilation system installed. Workers in air-line positive pressure respirators. No breakthrough on under hood sampling. 
Table 1

Results Summary

Mean/Median TNT air

concs $\left(\mathrm{mg} / \mathrm{m}^{\wedge} 3\right)$; (anemia

cases)
Mean Hgb Chg p-value (alpha 0.05)
(g/dL) 2-tail / 1-tail

95\% CIs

\begin{tabular}{lrlr}
\hline $0.12 / 0.07$ (0 anemia) & -0.280 & $0.189 / 0.0945$ & $(-0.174,0.154)$ \\
$0.23 / 0.16(0$ anemia $)$ & 0.125 & $0.489 / 0.245$ & $(-0.258,0.510)$ \\
$0.27 / 0.10(0$ anemia $)$ & 0.358 & $0.090 / 0.045$ & $(-0.065,0.782)$ \\
$0.31 / 0.27$ (4 anemia) & 0.594 & $0.001 / 0.0005$ & $(0.277,0.910)$ \\
$0.47 / 0.47(3$ anemia $a m)$ & 0.478 & $0.021 / 0.0105$ & $(0.081,0.875)$ \\
$0.47 / 0.47(1$ anemia $)$ & 0.493 & $0.002 / 0.001$ & $(0.215,0.771)$ \\
$0.70 / 0.40(4$ anemia $)$ & 0.577 & $0.006 / 0.003$ & $(0.200,0.950)$ \\
$1.31 / 1.24(3$ anemia $)$ & 0.490 & $0.029 / 0.0145$ & $(0.056,0.923)$ \\
\hline
\end{tabular}

Simple linear regression for mean hemoglobin concentration changes (preexposures minus during-exposures) on mean TNT air sampling concentrations for lowest 4 mean TNT values $\left(0.12 \mathrm{mg} / \mathrm{m}^{\wedge} 3-0.31 \mathrm{mg} / \mathrm{m}^{\wedge} 3\right)$ revealed a strong positive linear association with Pearson Correlation Coefficient of $r=0.996$. The $p$-value of B1 was p=0.004 (Table 1 and Figure 1). The association broke down, however, at mean TNT air concentrations above the $0.31 \mathrm{mg} / \mathrm{m}^{\wedge} 3$ level. Physiologically this may be secondary to bone marrow response to falling hgb concentrations.

Table 2

Regression model summary and parameter estimates.

\begin{tabular}{lccccccc}
\hline & \multicolumn{9}{c}{ Model Summary } & & \multicolumn{2}{c}{ Parameter Estimates } \\
\cline { 2 - 8 } Equation & R Square & $\mathrm{F}$ & $\mathrm{df1}$ & $\mathrm{df2}$ & Sig. & Constant & b1 \\
\hline & & & & & & & \\
Linear & .993 & 277.350 & 1 & 2 & .004 & -.958 & 4.906 \\
\end{tabular}




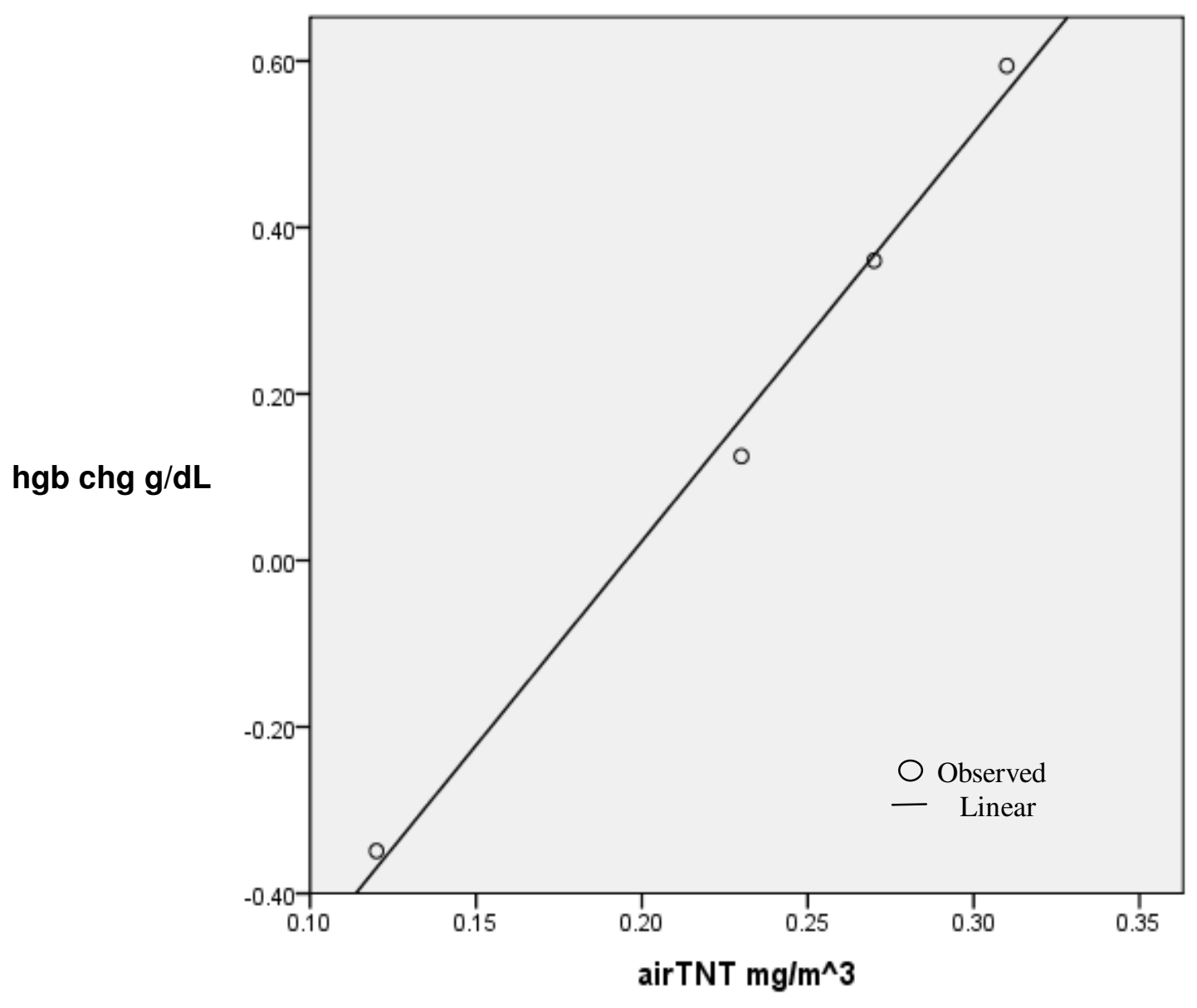

Figure 1. Mean hemoglobin changes regressed on mean TNT air concentrations for TNT concentration values $0.12 \mathrm{mg} / \mathrm{m}^{\wedge} 3$ to $0.31 \mathrm{mg} / \mathrm{m}^{\wedge} 3$. 


\section{Discussion}

Utilizing the TNT PEL $\left(1.2 \mathrm{mg} / \mathrm{m}^{\wedge} 3\right)$, REL $\left(0.4 \mathrm{mg} / \mathrm{m}^{\wedge} 3\right)$, and TLV $\left(0.08 \mathrm{mg} / \mathrm{m}^{\wedge} 3\right)$ $10 \mathrm{hr}$ TWAs as benchmarks, the results of this study show that mean and median TNT air concentrations about the TLV were protective against anemia and statistically significant hemoglobin changes in those respiratory protected workers who are at risk for anemia per the TNT skin absorption route (ref. to first 3 groups above in results section). A question does remain, however, as to what the anemia risk might be for those workers who work below the TLV and, hence, do not 'require' respiratory protection. With these first 3 groups, it is unlikely that these workers are not absorbing any TNT at all; they are more than likely receiving inconsequential doses with regard to anemia formation (ie, a burden that the body can handle effectively). Two out of these three groups were in full face negative pressure air purifying respirators, so there was the possibility of breakthrough. However, even if some break through occurred, it evidently did not affect these 2 groups. The other group was in positive pressure air-lines that revealed no breakthrough on under hood BZ sampling (this sampling was not part of the present study, but was conducted shortly after the air-line system was installed in the loading facility).

The results obtained from the last 5 groups of workers above appear to confirm the necessity for the skin notation for the PEL and REL particularly. Mean and median TNT air concentrations about the REL and PEL were not protective against anemia or statistically significant hemoglobin change (reduction) in those workers who were respiratory protected, but at risk for anemia per the TNT skin absorption route. 
This is the first known study, that the investigator is aware of, that looked at anemia risk and statistically significant hemoglobin concentration change in respiratory protected TNT munitions workers. The assumption is that the dermal route is the main TNT absorption danger for these workers; negative pressure respirator breakthrough and ingestion routes were probably minimal. In evaluating the dermal absorption problem in the past at the plant, the industrial hygienist confirmed that the cotton coveralls provided no barrier to TNT vapor contacting the skin. Although intuitive that TNT vapor was in contact with skin, he confirmed this by using Webster's reagent on the skin of munitions workers post shift in a non-TNT setting. Webster's reagent is an old colorimetric indicator of TNT presence that was developed in the 1920s; on contact with TNT it changes to a dark red color. This testing, along with literature precedents of dermal TNT absorption and TNT induced anemia in man and in animal modeling (see Introduction), plus similar observations at the plant that mirrored this study, revealed that it is more likely than not that TNT induced hemoglobin reduction and the development of anemia cases came about through the skin absorption of TNT. An attempt at dermal absorption control that was tried at the plant was the use of Tyvek suits. This was infeasible due to lack of heat dissipation in an already hot environment, and more dangerously, due to the generation of static electricity.

Part of the plant's SOP on TNT medical monitoring, which the investigator authored, provided for the kind of trend analysis done here in this study. It became apparent early on that anemia cases (plant-wide in all open TNT operations) were random, as there did not appear to be any correlations to duration of time in building, personal BZ air monitoring levels, repeat cases, particular work stations, time spent at 
particular work stations, personal hygiene, sex, ethnicity, medications used, etc. as to whom and when anemia would become evident (previous investigation at plant 2004). As an aside, even though age was not predictable as to who became anemic, the experience has been that the older workers with anemia took longer to recover than the younger workers. Another study at the plant looked into the above factors again; and even included a TNT urine metabolite, 4-aminodinitrotoluene (ADNT) (non-standardized test). This test showed no correlation with anemia cases, duration of time in TNT building, particular work stations, duration of time at a particular work station, age, or sex. In fact, there were only nine 4-aminodinitrotoluene positives in 112 post-shift TNT worker samples taken; and in only one of these nine positives did a worker have anemia (out of a total of 23 anemia cases from the 112 tested). The possibility of lab error though could not be ruled out, as this test has never been done on a routine basis (unpublished data, ammunition plant). Anemia cases at the plant could appear after just 1 or 2 days post exposure, after a few months, or not at all. With the anemia cases in this present study, there were no repeats; every anemia case was a different worker. Whether this was due to job rotation, lack of respirator compliance (or large breakthroughs) in those who became anemic, or individual susceptibilities with regard to marrow response timing and intensity, is unknown. If there were repeaters (there were some repeaters at the plant overall, but no repeaters in this study), in general it may be easier to discover a problem (ie, lack of hygiene, broken respirator, medication use, missed medical history, etc.). For the reasons stated above, it was decided to look at whole groups of workers in the TNT environments at monthly cross sections with TNT air concentrations and associated hemoglobin changes to see what might be going on with the workers as a 
cohort (see materials and methods section above). The questions then became: (1) Are statistically significant mean hemoglobin changes predictive of the development of anemia cases, and (2) At what mean TNT air concentrations are these phenomena occurring? This method of surveillance seemed to fit well with newer plant administrative policies of job rotation, enhanced personal hygiene emphasis, and providing and laundering all work clothes (under garments included). The administrative control of worker rotation involved rotations in and out of the TNT buildings, and rotations in and out of higher exposure areas within the TNT buildings; management took the initiative to implement this secondary to the air sampling data, even though our hemoglobin data revealed no conclusive patterns of susceptibility. Any anemia cases would be removed from exposure and followed up in clinic, and results of the statistical analyses and the number of anemia cases would be shared with $\mathrm{IH}$, engineering, management, and the safety office.

When during-exposure labwork indicated the onset of anemia, the worker was pulled from open TNT and a clinical evaluation took place looking for alternative causes to explain the anemia (ie, menses, blood donation, new disease status such as pernicious anemia, new meds, etc.). Symptoms were addressed (fatigue, tiredness, orthostasis, headaches, etc.), as well as problems related to PPE, rotation schedule, and personal hygiene. A physical exam took place focusing on vital signs, spO2, presence of splenomegaly, pallor, and cyanosis; the lack of physical findings was usually the rule. Out of the many anemia cases pulled over the years the investigator was at the plant, the only effect modifiers recalled were menses and blood donation. The clinic always considered anemia as caused by TNT unless proven otherwise. One case of pernicious 
anemia did develop in a worker who, once treated with B12 and recovered, was permitted back into the TNT environment. Virtually all cases of TNT induced anemia resolved once the worker was removed from exposure; the recovery time usually took from 30 to 60 days, at which time they were permitted re-entry into the TNT buildings (most desired return due to a hazard pay differential; but others did not want to go back into the environment, their decisions were supported by the clinic and the plant, and the plant usually found work for them in alternative operations). The anemia cases over the years the investigator was at the plant were best characterized as mild hemolytic anemia. The most notable finding was a normocytic, normochromic anemia, which sometimes was supported by reticulocytosis, low haptoglobin, and high AST and LDH levels. Conspicuously absent were bite cells, Heinz bodies, and schistocytes, however. As with this study, the anemia cases were usually very mild with no worker usually surpassing a $10 \%$ reduction in hemoglobin concentration; the worst case recalled (not in this investigation) was a loss of $33 \%$ with a recovery time of 120 days in an otherwise healthy 23 year old runner. Also, with regard to recovery time, the older the worker, the longer the recovery time (perhaps 90 to 120 days). Of all TNT induced anemics there was only one older worker who did not recover; fortunately he did not appear to worsen either. $\mathrm{He}$ had no other medical problems and was not on any medications; a full work-up by his primary care physician revealed no other apparent causative factor(s). He had been working in TNT for 3 or 4 months. After 180 days out of TNT operations he was put into the comp system, but was free to follow-up at any time for a $\mathrm{CBC}$ at the plant clinic. $\mathrm{He}$ was permanently removed from TNT exposure and placed on another plant operation that was TNT free (this case not part of present study). 
Shortcomings of this study include less than robust TNT air sampling sample numbers per group. Statistical sampling would have been desirable, but was very cost prohibitive. For this reason both the mean and median were used in this study to cover normality and lognormality (non-parametric). Interestingly, both values per group were relatively close to one another when measuring against the PEL, REL, and TLV benchmarks. Another shortcoming may be the lack of use of NIOSH recommended airline respirators for open TNT work in the 6 groups working in the demil facility. These workers wore NIOSH approved 3M or North negative pressure air purifying respirators supplied with organic vapor and HEPA filter combination cartridges instead (ie, NIOSH approved 60921 organic vapor cartridge and P100 (HEPA) particulate filter). As of this writing the demil facility does now have air-line respirators in place. This shortcoming is likely not detrimental, as the use of appropriate NIOSH approved combination cartridges, NIOSH approved full face respirators, and the clinic's very robust respiratory protection program, should put the APF at 50 (5 orders of magnitude greater than the NIOSH recommended supplied air respirator of at least APF 10 for TNT levels up to $5 \mathrm{mg} / \mathrm{m}^{\wedge} 38$ hr TWA) (29CFR1910.134)

Per the inclusion criteria, due to the observational nature of the study, workers were not controlled for time exposed to open TNT. Rotations on and off the operation, as well as rotations within the operation took place regularly. Also, those who became anemic were pulled out of the operation by plant medical personnel thus taking away from the worker complement of the operation. There were workers who remained for more than one round of sampling, and there were workers put into the operation maybe 23 days before a follow-up during-exposure hemoglobin level was to be drawn. This 
process continued throughout the 8 sampling periods. Conceivably there could be carryover problems (bias away from null) from workers staying in for 1 or 2 rounds of followup during-exposure sampling. Conversely, minimal exposure for those who may have entered the cycle only a couple of days before a sample was to be taken could conceivably bias the group towards the null. But, as stated above, the previous experience with looking at exposure duration times and anemia development revealed no correlation; this lack of correlation is supported by Gribova (1983) and Army (1976). Therefore, the issue with job rotation may not be detrimental to this study. In fact, the rotations were business as usual, so from an observational standpoint, for the convenience samples used here, internal validity was met. External validity would certainly be based on operational, PPE, administrative controls, and engineering controls similarities to our samples, so generalizeability may, or may not be appropriate depending on the circumstances. No attempt in the analysis was made to control for carry-over using general estimating equations (GEE) or Latin Squares.

The cause for no correlation between exposure time and anemia development could most likely be due to individual differences in bone marrow response timing and intensity (and as a caveat, to the timing of the medical monitoring lab work with regard to where a particular worker might be in his / her marrow response when the blood is drawn). To best judge what may be going on overall with regard to differing individual susceptibilities and responses in otherwise healthy workers (per exclusion criteria) would be to look at what is going on with all workers in a particular single building operation, such as was done here. It may be that at those lower TNT air concentrations most workers can amount a sufficient marrow response that does not generate a statistically 
significant mean hemoglobin concentration drop for the whole group (especially pronounced at the lowest mean TNT level in the study, group 1 in the results section above, where the group was actually able to generate a mean hemoglobin concentration that was greater than their pre-exposure baselines (although not a statistically significant increase), even though there was no different process in place as far as job rotations in and out of the building, and job rotation work station to work station within the building. The finding with this group, as relates to the TNT air concentration level, was probably the natural dilution ventilation that was maintained throughout 2-3 weeks during a warm spell in October of 2006 rendering a mean TNT $10 \mathrm{hr}$ TWA of $0.12 \mathrm{mg} / \mathrm{m}^{\wedge} 3$ (median $0.07 \mathrm{mg} / \mathrm{m}^{\wedge} 3$ ) in the building). The converse is probably true at higher TNT air concentrations where some workers cannot mount an effective marrow response, or their response time is longer in coming, compared to other workers. Since bone marrow biopsies are out of the question, and reticulocytosis rare until after removal from TNT (Army, 1976; Stewart, 1945), the results of this study at least show that as statistically significant mean hemoglobin drops become apparent, it may be time to expect some anemia cases.

The simple regression modeling done here is revealing in that there is a predictable linear group 'dose'-response occurrence with regard to mean hemoglobin change as a function of mean TNT air concentrations from $0.12 \mathrm{mg} / \mathrm{m}^{\wedge} 3$ to $0.31 \mathrm{mg} / \mathrm{m}^{\wedge} 3$. This is not inconsistent with the dose-response findings described by Gribova, 1983; Army, 1976; Bodeau, 1993; and El Ghawabi, 1974. This relationship breaks down at the higher TNT levels in the study (model not depicted in results section). At levels above $0.31 \mathrm{mg} / \mathrm{m}^{\wedge} 3$ there was no linear association evident. This may reflect the group bone 
marrow response to replace damaged erythrocytes, with the majority of workers having a marrow response that levels out their hemoglobin change but does not resolve it back to baseline. It may be that there is a step-wise phenomenon at play here with the marrow able to respond to increasing RBC destruction by leveling off at certain TNT doses; and as the dose increases it is followed by another drop followed by another leveling, and so forth, until aplasia happens at some critical TNT load and leveling or recovery are not possible. Of note, the three lowest TNT values, and concomitant hemoglobin difference levels, were all independent, as they were taken from demil dayshift, demil night shift, and load dayshift, respectively.

This study does suggest that, despite likely individual worker bone marrow responses with resistance / susceptibility to anemia at given TNT doses, the average ambient TNT air concentration appears predictive as to the development of anemia cases in worker groups in respiratory protection (at least in the groups studied here; may not be entirely generalizeable to other operations). Which particular individual worker(s) within the group(s) actually become anemic is another matter. The mean and / or median ambient TNT air concentrations could be used to evaluate engineering controls to reduce the mean/median to levels close to the TLV, provided worker rotation is part of the exposure reduction plan as well.

Alternative causes to explain the anemia cases and hemoglobin drops in the groups besides TNT exposure were considered. Normal fluctuation in healthy persons' hemoglobin levels, which would be quite narrow over the time period studied here, were considered, but due to sufficient a priori evidence of the association between TNT and anemia and hemoglobin drop, this natural fluctuation was taken to be only a small effect 
modifier without much significance (ie, results not likely due to chance). Furthermore, the conditions of work for these munitions workers may be more conducive to hemoconcentration rather than anemia if they were not working with open TNT. Factors such as negative pressure respirator wear leading to a more labored breathing with possible small oxygen desaturations, and manual labor necessitating increased oxygen demand may be factors in creating a relative polycythemia. Dehydration from the hot environment could contribute to hemoconcentration as well. In order to better characterize these factors, an independent control group would have been necessary; unfortunately this option was not available for this study.

Standard Morbidity Ratios (SMRs) were not calculated for anemia in these workers over anemia in the general population. The Healthy Worker Effect (HWE) bias most certainly would have the general population with a higher proportion of anemics due to old age considerations. An age stratification was not attempted here.

Furthermore, the anemia cases in this study all resolved back to their pre-exposure nonanemic baselines once they were removed from open TNT for a sufficient amount of time (ie, no stable prevalence).

As a last point in helping further substantiate the TNT skin absorption route as important, is that there appeared to be no real difference in protection from anemia cases and mean hemoglobin drops between the 2 groups in air-line respirators and the 6 groups wearing the negative pressure air purifying respirators.

Lastly, this study adds to the body of knowledge already in existence that there should be a consideration of a new TNT OSHA PEL based on the present ACGIH TLV of $0.1 \mathrm{mg} / \mathrm{m}^{\wedge} 3(8 \mathrm{hr}$ TWA $)$. 


\section{References}

American Conference of Governmental Industrial Hygienists (2001). Documentation of the threshold limit values, 2-4-6, trinitrotoluene TLV-TWA summary. Cincinnati: ACGIH Worldwide Signature Publications.

Army Environmental Hygiene Agency (1976). Occupational health special study no. 32049-75/76 adverse health effects of selected explosives (TNT, RDX) January November 1975. US Army Environmental Hygiene Agency, 1-14.

Bodeau D. T. (1993). Chapter 9, Military energetic materials: Explosives and propellants. In Brigadier General Russ Zajtchuk (Ed), Textbook of military medicine Part III vol. 2: Occupational health the Soldier and the industrial base (pp. 329-339). Falls Church Virginia: Office of the Surgeon General U. S. Department of the Army.

Bradley, M. D. (2005). TNT worker laboratory biosurveillance SOP. Local standing operating procedure, MCAAP-OHC.

Channon, H. J., \& Mills, G. T. (1944). The metabolism of 2,4,6-trinitrotoluene. Biochemical Journal, 38, 70-85.

Cone, T. E. (1944). A review of the effects of trinitrotoluene (TNT) on the formed elements of blood. Journal of Industrial Hygiene and Toxicology, 26, 260-263.

Crawford, M. A. D. (1954). Aplastic anemia due to trinitrotoluene intoxication. British Medical Journal, 2, 430-437.

Department of the Army Technical Manual TM 9-1300-214. (1984). Military Explosives. Washington, D. C.: Headquarters Department of the Army.

Dacre, J. C., \& Rosenblat, D. H. (1974). Mammalian toxicology and toxicity to aquatic organisms of four important types of waterborne munition propellants - An extensive literature review. USAMBROL technical report 7403.

Deutsche Forschungsgemeinschaft (DFG). (1991). Occupational toxicants: Critical data evaluation for MAK values and classification of carcinogens vol 1 (pp. 359-387). German commission for the investigation of health hazards of chemical compounds in the work area. New York: VCH Publishers. 
Dilley, J. V., \& Tyson, C. A. (1982). Short term oral toxicity of 2,4,6-trinitrotoluene in mice, rats, and dogs. Journal of Toxicology and Environmental Health, 9(4), 565585.

Djerassi, L. S., \& Vitany, L. (1975). Haemolytic episode in G6PD deficient workers exposed to TNT. British Journal of Industrial Medicine, 32, 54-58.

Eddy, J. H. (1944). Aplastic anemia from responses to TNT well below $1.5 \mathrm{mg} / \mathrm{m}^{\wedge} 3$. Journal of the American Medical Association, 125, 1169-1172.

El-Ghawabi, S. H., \& Ibrahim, G. A. (1974). Trinitrotoluene exposure. Ain Shame Medical Journal, 25, 545-549.

Gribova, I. A., Gabulgalimova, R. A., \& Dymova, E. G. (1983). Changes in the blood under the effect of low concentrations of trinitroaminotoluene (A clinical and experimental study). Gig. Tr. Prof. Zabol, 9, 24-28.

Hart, W. L., \& Ley, E. B. (1944). A report of four cases of aplastic anemia. Industrial Medicine, 3, 896-899.

Hathaway, J. A. (1977). Trinitrotoluene: A review of reported dose-related effects provideing documentation for a workplace standard. Journal of Occupational Medicine, 19, 341-345.

Hunter, D. (1978). The Diseases of Occupations (6ed), 522-530. London: Hodder \& Stoughton.

LaDou, J. (2007). Current Occupational and Environmental Medicine (4ed), 210-220. New York: Lange McGraw Hill.

Lemberg, R., \& Callaghan, J. P. (1945). Metabolism of aromatic nitro-compounds, 3. Isolation of reduction products of 2,4,6-trinitrotoluene from the urine of rats and from human urine. Australian Journal of Experimental Biology and Medical Science, 23, 13-20.

Levine, B. S., Furedi, E. M., \& Gordon, D. E. (1984). Subchronic toxicity of trinitrotoluene in Fischer 344 rats. Toxicology, 32, 253-265.

Levine, B. S., Rust, J. H., \& Barkley, J. J. (1990). Six-month oral toxicity study of trinitrotoluene in Beagle dogs. Toxicology, 63, 233-244.

Liu, Y. Y., Lu, A. Y. H., \& Steams, R. A. (1992). In vivo covalent binding of C14 trinitrotoluene to proteins in the rat. Chemical Biological Interactions, 82, 1-19. 
McConnell, W. J., \& Flinn, R. H. (1946). Summary of twenty-two trinitrotoluene fatalities in World War II. Journal of Industrial Hygiene and Toxicology, 28, 7686.

NIOSH Pocket Guide to chemical Hazards (2005). 2,4,6-Trinitrotoluene. National Institute for Occupational safety and health: Publication number 2005-149. Retrieved November 21, 2007 from www.cdc.gov/niosh/npg/npgd0641.html.

Opresko, D. M. (2004). Toxicity summary for 2,4,6-trinitrotoluene. Oak Ridge National Laboratory: Chemical hazard evaluation group of the biomedical and environmental information analysis section. Retrieved September 15, 2005 from www.rais.ornl.gov/tox/profiles/2_4_6_trinitrotoluene.doc.

OSHA sampling and analytical method no. 44 for 2,4,6-trinitrotoluene and 2,4dinitrotoluene (1983). U. S. Department of Labor. Retrieved October 20, 2007 from www.osha.gov/dts/sltc/methods/organic/org044/org044.html.

OSHA 29CFR1910 General Industry Regulations (USF SafetyFlorida Consultation group version) (2007 ed). 29CFR1910.134, pp. 193 table 1; 29CFR1910.1000, pp. 438 table Z-1. Davenport, Iowa: Mangan Communications, Inc.

Perkins, J. L. (1997). Modern Industrial Hygiene, Recognition and evaluation of chemical agents. New York: Van Nostrand Reinhold.

Richter-Torres, P., Dorsey, A., \& Hodes, C. S. (1995). Toxicological Profile for 2,4,6Trinitrotoluene. US Department of Health and Human Services, Public Health Service, Agency for Toxic Substances and Disease Registry (ATSDR). Retrieved on October, 2005 from www.atsdr.cdc.gov/toxprofiles/tp81.pdf

Sabbioni, G., Yu-Ling, L., Huifang, Y., \& Sepai, O. (2005). Hemoglobin adducts, urinary metabolites and health effects in 2,4,6-trinitrotoluene exposed workers. Carcinogenesis, 26(7), 1272-1279.

Stewart, A., Witts, L. T., Higgins, G., \& O'Brien, J. R. (1945). Some early effects of exposure to trinitrotoluene. British Journal of Industrial Medicine, 2, 74-82.

Technische Regeln fur Gefahrstoffe (TRGS 900), (2007). Arbeitsplatzgrenzwerte fur trinitrotoluol, pp. 30. Retrieved on September, 2007 from www.baua.de

Voegtlin, C., Hooper, C. O., \& Johnson, J. M. (1921). Trinitrotoluene - its nature, diagnosis, and prevention. Journal of Industrial Hygiene and Toxicology, 28, 239-254.

Wikipedia (2008). Trinitrotoluene. Retrieved January, 2009 from http://en.wikipedia.org/wiki/trinitrotoluene. 
Woolen, B. H., Hall, M. G., \& Craig, R. (1986). Trinitrotoluene: Assessment of occupational absorption during manufacture of explosives. British Journal of Industrial Medicine, 43, 465-473.

Zaklady Chemiczne 2,4,6-trinitrotoluene safety data sheet of dangerous substance (Polish MSDS equivalent) (21August2003). Nitro-chem SA w Bydgoszczy, Wojska, Polskiego 65A. 